\title{
Synthesis and Properties of Organosoluble Poly(amide-imide-imide)s Based on Tetraimide-Dicarboxylic Acid Condensed from 4,4'-(Hexafluoroisopropylidene)diphthalic Anhydride, 1,4-Bis(4-aminophenoxy)benzene, and Trimellitic Anhydride, and Various Aromatic Diamines
}

\author{
Chin-Ping Yang, ${ }^{\dagger}$ Ruei-Shin Chen, and Ming-Jui Wang \\ Department of Chemical Engineering, Tatung University, 40 Chungshan North Road, \\ Section 3, Taipei 104, Taiwan, Republic of China
}

(Received November 1, 2001; Accepted January 9, 2002)

\begin{abstract}
A novel tetraimide-dicarboxylic acid (I) was synthesized starting from the ring-opening addition of 4,4'-(hexafluoroisopropylidene)diphthalic anhydride (6FDA), 1,4-bis(4-aminophenoxy)benzene (TPEQ), and trimellitic anhydride (TMA) at a 1:2:2 molar ratio in $N$-methyl-2-pyrrolidone (NMP), followed by azeotropic condensation to the diacid I. A series of poly(amide-imide-imide)s (PAIIs) with inherent viscosities of $1.0-1.3 \mathrm{dL} \mathrm{g}^{-1}$ was prepared from the diacid I with various aromatic diamines by direct polycondensation. Most of the PAIIs were readily soluble in a variety of amide polar solvents, and even in less polar $m$-cresol and pyridine. Solvent-cast films had a tensile strength ranging from 80 to $101 \mathrm{MPa}$, elongation at break from 10 to $17 \%$, and initial modulus from 2.0 to $2.4 \mathrm{GPa}$, and all of them exhibited clear yield points on their stress-strain curves. The glass transition temperature of these PAIIs was recorded at $260-289^{\circ} \mathrm{C}$. They had $10 \%$ weight loss at a temperature above $520^{\circ} \mathrm{C}$ in air or nitrogen atmosphere.

KEY WORDS Tetraimide-Dicarboxylic Acid / Organosoluble / Poly(amide-imide-imide)s / Direct

Polycondensation /
\end{abstract}

Aromatic polyimides are well-known as high performance polymeric materials due to their excellent thermal stability, electric insulation property, and chemical resistance. ${ }^{1-7}$ Polyimides are mainly used in the aerospace and electronic industries in the forms of films and moldings. However, the applications are limited due to their high softening or melting temperatures and their insoluble nature in most organic solvents. To overcome these drawbacks, the modifications of polyimide structure are often be used, for example the introduction of flexible linkages, non-symmetrical structure, or bulky substituents into polymer backbones. ${ }^{8-13}$ The other method is by using copolymerization to synthesize copolymers to improve processability, such as poly(amide-imide) (PAI). ${ }^{14,15}$

Aromatic PAIs possess desirable characteristics with merits of both polyamides and polyimides such as high thermal stability and good mechanical properties as well as easy processability. These polymers can be synthesized from various aromatic monomers containing dianhydride, diamine, dicarboxylic acid, amino acid, or anhydride-acid by polycondensation. PAIs usually have been synthesized through several main routes. The first route goes through the amide-imide-forming reaction, by which trimellitic anhydride (TMA) reacts either with diisocyanate to produce $\mathrm{PAI}^{16-19}$ or with thionyl chloride to synthesize TMA-chloride before the

${ }^{\dagger}$ To whom correspondence should be addressed. latter and diamine can produce PAI. ${ }^{20}$ The second route goes through the imide-forming reaction, with amidecontaining monomer serving as a medium; for example, amide-containing diamine is polycondensed with dianhydride to provide the poly(amide amic acid), which is then dehydrated to obtain PAI. ${ }^{21,22}$ The third route goes through the amide-forming reaction from imidecontaining monomers such as dicarboxylic acids or diamines. Imide-containing dicarboxylic acids usually come from the thermal imidization of diamines and TMA,${ }^{23-25}$ from the condensation of dicarboxylic anhydride and amino acids, ${ }^{26-28}$ or from the dehydration of aromatic amino acids and TMA. ${ }^{29-31}$ Then, these resultant imide-containing dicarboxylic acids react with aromatic diamines to synthesize aromatic PAIs by polycondensation.

In our laboratory, the dicarboxylic acid, 1,4-bis(4trimellitimidophenyoxy)benzene, was prepared from TMA and 1,4-bis(4-aminophenoxy)benzene (trivially termed triphenyl ether hydroquinone diamine, referred to as TPEQ). A series of aromatic PAIs was synthesized from the dicarboxylic acid and various aromatic diamines. ${ }^{32}$ However, these polymers showed limited solubility and poor tensile properties. Thus, this research describes the synthesis of novel PAIIs to modify their tensile properties and process. 6FDA, TPEQ, and TMA were used to prepare a new-type tetraimidedicarboxylic acid (TIDA), which then reacted with vari- 
ous aromatic diamines to form PAIIs $\left(\mathbf{I V}_{\mathrm{a}-\mathrm{m}}\right)$ by direct polycondensation. Various properties of the resultant PAIIs, specifically, their solubility, tensile properties, and thermal stability, will be investigated and compared with those of corresponding PAIs.

\section{EXPERIMENTAL}

\section{Materials}

$p$-Phenylenediamine ( $\mathbf{I I I}_{\mathrm{a}}$; from Tokyo Chemical Industry, TCI) and $m$-phenylenediamine ( $\mathbf{I I I}_{\mathrm{b}}$; from TCI) were vacuum-distilled before use. Other diamines including 2,4- diaminotoluene (III ; from TCI), 4,4'oxydianiline (III ${ }_{\mathrm{d}}$; from TCI), 4,4'-methylenedianiline (III ${ }_{\mathrm{e}}$; from TCI), 4,4' ${ }^{\prime}$-thiodianiline ( $\mathbf{I I I}_{\mathrm{f}}$; from TCI), 1,4-bis(4-aminophenoxy)benzene (TPEQ) (III ; from TCI), 1,3-bis(4-aminophenoxy)benzene (III $;$;rom Chriskev), 2,2-bis[4-(4-aminophenoxy)phenyl]propane (III ${ }_{j}$; from Chriskev), 2,2-bis[4-(4-aminophenoxy)phenyl]hexafluoropropane ( III $_{\mathrm{k}}$; from TCI), bis[4-(4aminophenoxy)phenyl]sulfone ( $\mathbf{I I I}_{1}$; from Chriskev), and bis[4-(3-aminophenoxy)phenyl]sulfone $\quad$ (III $_{\mathrm{m}}$; from Chriskev) were used as received. According to a reported method, ${ }^{33}$ 1,2-bis(4-aminophenoxy)benzene (III i $_{\mathrm{i}}$ was prepared by the nucleophilic substitution reactions of the corresponding aromatic diol and $p$-chloronitrobenzene followed by catalytic hydrazine reduction. Trimellitic anhydride (TMA; from Wako) and 4,4'-(hexafluoroisopropylidene)diphthalic anhydride (6FDA; from Chriskev) were used without further purification. The calcium chloride $\left(\mathrm{CaCl}_{2}\right.$; from Wako) was dried under vacuum at $180^{\circ} \mathrm{C}$ for $10 \mathrm{~h}$. $\mathrm{N}, \mathrm{N}$-Dimethylacetamide (DMAc; from Fluka), $\mathrm{N}$ methyl-2-pyrrolidone (NMP; from Fluka) and pyridine (Py; from Wako) were purified by distillation under reduced pressure over calcium hydride and stored over $4 \AA$ molecular sieves. Triphenyl phosphite (TPP; from TCI) was used as received.

\section{Synthesis of Tetraimide-Dicarboxylic Acid (I)}

$4.78 \mathrm{~g}(16 \mathrm{mmol})$ of TPEQ was first dissolved in $40 \mathrm{~mL}$ of NMP. After the monomer was completely dissolved, $3.55 \mathrm{~g}(8 \mathrm{mmol})$ of 6 FDA and $3.07 \mathrm{~g}(16 \mathrm{mmol})$ of TMA were added to it in one portion. The mixture was stirred at room temperature for $2 \mathrm{~h}$. About $10 \mathrm{~mL}$ of toluene was then added, and the mixture was heated at the reflux for about $3 \mathrm{~h}$ until about $0.6 \mathrm{~mL}$ of water was distilled off azeotropically via a Dean-Stark trap. After complete removal of water, the residual toluene was then distilled off under reduced pressure. After cooling, the obtained partial solution was trickled into water and the precipitated product was collected by filtration, washed several times with water, and dried in a vacuum to give sallow-powder diacid I; mp $342-344^{\circ} \mathrm{C}$ (by DSC).

IR $v_{\max }(\mathrm{KBr}): 3500-2500$ (carboxylic acid, $-\mathrm{OH}$ ), 1782 (symmetric imide $\mathrm{C}=\mathrm{O}$ stretching), 1724 (acid $\mathrm{C}=\mathrm{O}$ stretching and asymmetric imide $\mathrm{C}=\mathrm{O}$ stretching), 1382 (imide, imide ring vibration, axial), 1118 (imide, imide ring vibration, transverse), and $723 \mathrm{~cm}^{-1}$ (imide, imide ring vibration, out of plane). ${ }^{1} \mathrm{H}$ NMR [dimethyl sulfoxide (DMSO)- $d_{6}$ ]: $\delta=8.42,8.41\left(\mathrm{H}_{\mathrm{b}}\right)$, $8.31\left(\mathrm{H}_{\mathrm{a}}\right), 8.19,8.17\left(\mathrm{H}_{\mathrm{i}}\right), 8.08,8.07\left(\mathrm{H}_{\mathrm{c}}\right), 7.98,7.96$ $\left(\mathrm{H}_{\mathrm{h}}\right), 7.76\left(\mathrm{H}_{\mathrm{g}}\right), 7.49,7.47,7.45\left(\mathrm{H}_{\mathrm{d}}+\mathrm{H}_{\mathrm{d}^{\prime}}\right), 7.21,7.20$, 7.17, $7.16\left(\mathrm{H}_{\mathrm{e}}+\mathrm{H}_{\mathrm{e}^{\prime}}+\mathrm{H}_{\mathrm{f}}+\mathrm{H}_{\mathrm{f}^{\prime}}\right) .{ }^{13} \mathrm{C}$ NMR (DMSO- $\left.d_{6}\right)$ : $\delta=168.42,168.40,168.26,168.13\left(\mathrm{C}^{2}, \mathrm{C}^{2^{\prime}}, \mathrm{C}^{2^{\prime \prime}}\right.$, $\left.\mathrm{C}^{2^{\prime \prime \prime}}\right), 167.86\left(\mathrm{C}^{1}\right), 159.10,158.96\left(\mathrm{C}^{12}, \mathrm{C}^{12^{\prime}}\right), 153.93$, $153.88\left(\mathrm{C}^{13}, \mathrm{C}^{13^{\prime}}\right), 138.99\left(\mathrm{C}^{17}\right), 138.14\left(\mathrm{C}^{6}\right), 137.44$ $\left(C^{15}\right), 137.08\left(C^{3}\right), 136.54\left(C^{8}\right), 134.63\left(C^{18}\right), 134.23$ $\left(\mathrm{C}^{20}\right), 133.65\left(\mathrm{C}^{5}\right), 130.76,130.64\left(\mathrm{C}^{10}, \mathrm{C}^{10^{\prime}}\right), 128.10$, $128.02\left(\mathrm{C}^{9}, \mathrm{C}^{9^{\prime}}\right), 125.86\left(\mathrm{C}^{19}\right), 125.26\left(\mathrm{C}^{4}\right), 125.09$ $\left(\mathrm{C}^{16}\right), 124.85\left(\mathrm{C}^{7}\right), 122.70,122.65\left(\mathrm{C}^{11}, \mathrm{C}^{11^{\prime}}\right), 119.47$ $\left(\mathrm{C}^{14}, \mathrm{C}^{14^{\prime}}\right), 129.19,126.29,123.39,120.49\left(\mathrm{C}^{21}\right.$, quartet, with $\left.{ }^{1} J_{\mathrm{CF}}=290 \mathrm{~Hz}\right), 65.37\left(\mathrm{C}^{22}\right.$, multiplet, with $\left.{ }^{2} J_{\mathrm{CF}}=25 \mathrm{~Hz}\right)$.

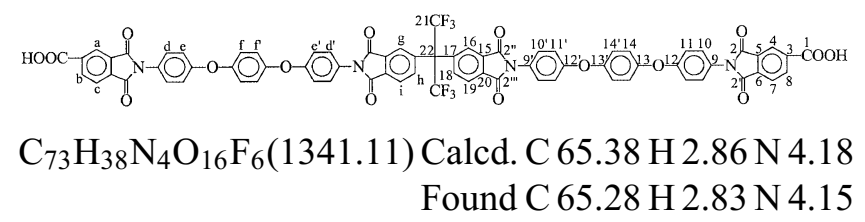

\section{Synthesis of Diimide-Dicarboxylic Acid (II)}

$2.34 \mathrm{~g}$ ( $8 \mathrm{mmol})$ of TPEQ was first dissolved in $16 \mathrm{~mL}$ of DMAc, and then $3.07 \mathrm{~g}(16 \mathrm{mmol})$ of TMA was added. After the mixture was completely dissolved, toluene was then added, and the mixture was heated at the reflux for about $3 \mathrm{~h}$ until water was distilled off azeotropically. The residual toluene was then distilled off under reduced pressure. After cooling, the obtained solution was trickled into methanol and the precipitated product was collected by filtration, and then recrystallized from DMF solvent. The purified product was dried under vacuum to obtain powder; $\mathrm{mp}$ $398-400^{\circ} \mathrm{C}$ (by DSC).

$\mathrm{C}_{36} \mathrm{H}_{20} \mathrm{~N}_{2} \mathrm{O}_{10}(640.56)$ Calcd. C 67.50 H 3.15 N 4.37 Found C 67.46 H 3.13 N 4.34

\section{Synthesis of Poly(amide-imide-imide)s}

A typical example of polycondensation is described as follows. A mixture of $1.34 \mathrm{~g}(1 \mathrm{mmol})$ of tetraimide-dicarboxylic acid $\mathbf{I}, 0.20 \mathrm{~g}(1 \mathrm{mmol})$ of $4,4^{\prime}$-oxydianiline $\left(\mathbf{I I I}_{\mathrm{d}}\right), 0.2 \mathrm{~g}$ of $\mathrm{CaCl}_{2}, 1.8 \mathrm{~mL}$ of Py, $0.6 \mathrm{~mL}$ of TPP, and $7.3 \mathrm{~mL}$ of NMP was heated while being stirred at $100^{\circ} \mathrm{C}$ for $3 \mathrm{~h}$. The viscosity of reaction solutions increased after $1 \mathrm{~h}$, and an additional $2.0 \mathrm{~mL}$ of NMP was added to the reaction mixture. At the 


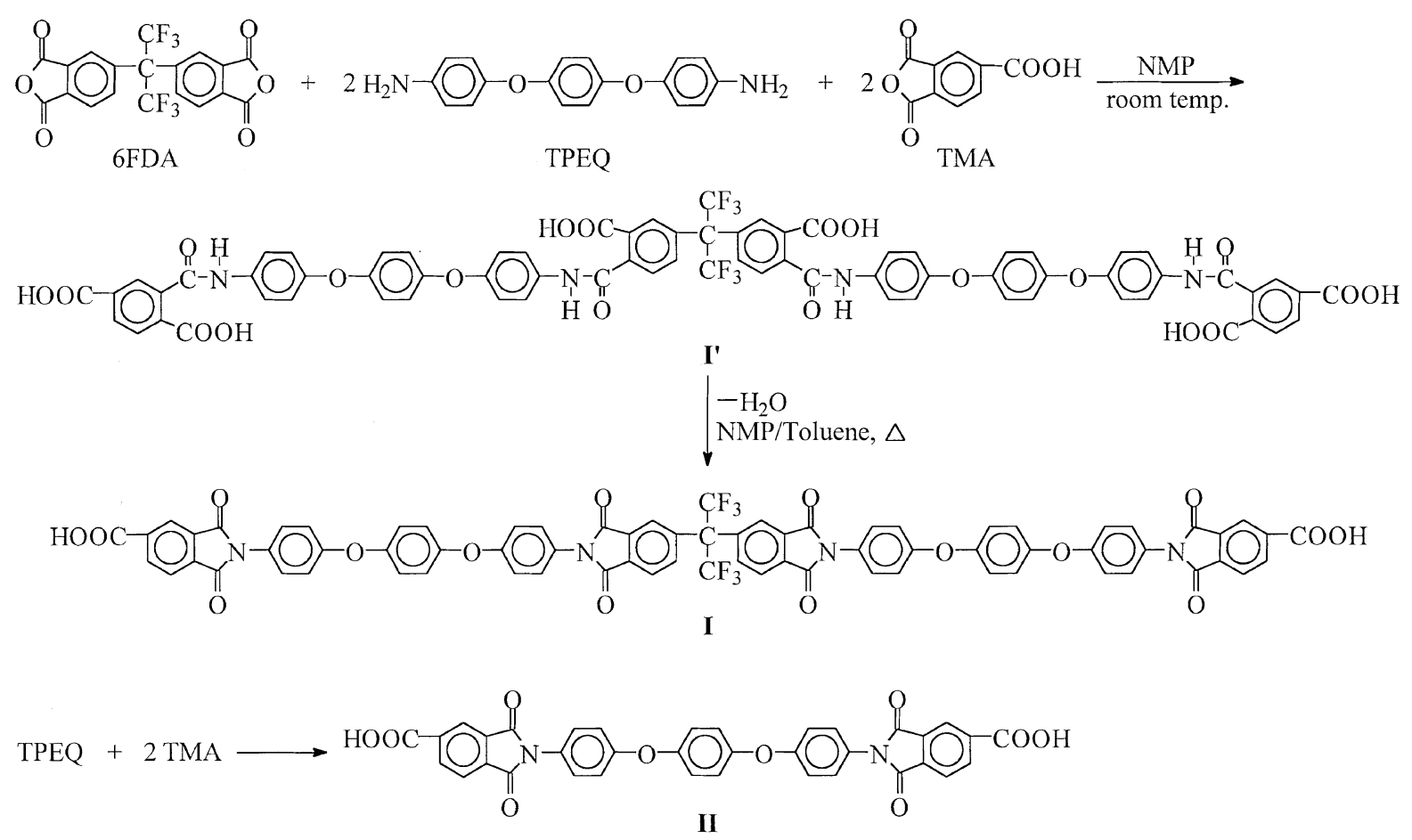

Scheme 1. Preparation of tetraimide-diacid I.

end of the reaction, the obtained viscous polymer solution was trickled into $400 \mathrm{~mL}$ of stirred methanol. The yellow-stringy polymer was washed thoroughly with hot water and methanol, collected by filtration and dried in a vacuum. The yield was $1.50 \mathrm{~g}$. The inherent viscosity of $\mathbf{I V}_{\mathrm{d}}$ in DMAc at a $0.5 \mathrm{~g} \mathrm{dL}^{-1}$ concentration at $30^{\circ} \mathrm{C}$ was $1.3 \mathrm{dL} \mathrm{g}^{-1}$. All other poly(amide-imideimide)s were synthesized in a similar procedure.

\section{Preparation of the Poly(amide-imide-imide) Films}

A polymer solution of approximately $10 \%$ was made by the dissolving of poly(amide-imide-imide) in DMAc. The solution was poured into a glass culture dish $9 \mathrm{~cm}$ in diameter that was placed in a $90^{\circ} \mathrm{C}$ oven overnight to remove the solvent. Then, the obtained semidried polymer film was stripped from the glass substrate and further dried in vacuum at $160^{\circ} \mathrm{C}$ for $6 \mathrm{~h}$. The obtained films were about $0.05 \mathrm{~mm}$ thick.

\section{Measurements}

Elemental analyses were performed on a PerkinElmer Model 2400 C, H, N analyzer. IR spectra were recorded on a Horiba Fourier-Transform Infrared Spectrometer FT-IR-720. ${ }^{1} \mathrm{H}$ and ${ }^{13} \mathrm{C}$ NMR spectra were determined on a JEOL EX-200 FT-NMR spectrometer. The inherent viscosities were measured with a Cannon-Fenske viscometer at $30^{\circ} \mathrm{C}$. Differential scanning calorimeter (DSC) traces were measured on TA Instruments DSC 2010 in flowing nitrogen $\left(40 \mathrm{~cm}^{3}\right.$ $\mathrm{min}^{-1}$ ) at a heating rate of $15^{\circ} \mathrm{C} \mathrm{min}^{-1}$. Thermogravimetry analysis (TGA) was conducted with a TA
Instruments TGA 2050, and experiments were carried out on $10 \pm 2 \mathrm{mg}$ samples heated in flowing nitrogen or air $\left(100 \mathrm{~cm}^{3} \mathrm{~min}^{-1}\right)$ at a heating rate of $20^{\circ} \mathrm{C} \mathrm{min}^{-1}$. An Instron Universal Tester Model 1130 with a load cell of $5 \mathrm{~kg}$ was used to study the stress-strain behavior of the polymer film. A gauge of $2 \mathrm{~cm}$ and a strain rate of $5 \mathrm{~cm} \mathrm{~min}{ }^{-1}$ were used for this study. Measurements were performed at room temperature with film specimens $(0.5 \mathrm{~cm}$ wide, $6 \mathrm{~cm}$ long, and about $0.05 \mathrm{~mm}$ thick) and an average of at least five individual determinations was adopted.

\section{RESULTS AND DISCUSSION}

\section{Monomer Synthesis}

TIDA I was prepared starting from the ring-opening addition of TPEQ, 6FDA, and TMA in a 2:1:2 molar ratio at room temperature in amide-type solvent (such as DMAc or NMP), followed by the intramolecular cyclodehydration of the intermediate tetraamidehexacarboxylic acid $\left(\mathbf{I}^{\prime}\right)$, as shown in Scheme 1. For the synthesis of imide-containing dicarboxylic acid, pure diimide-dicarboxylic acid II was easily obtained, because the aromatic amine groups of TPEQ hardly reacted with the carboxylic acid group of TMA in pure solvent. For the synthesis of TIDA I, the addition of TPEQ, 6FDA, and TMA might not form the structure of intermediate $\mathbf{I}^{\prime}$ completely in the initial period, and some other diacids were produced. However, the exchange reaction of amic acid was carried out during a long time of stir $^{34}$ and the product with the low- 


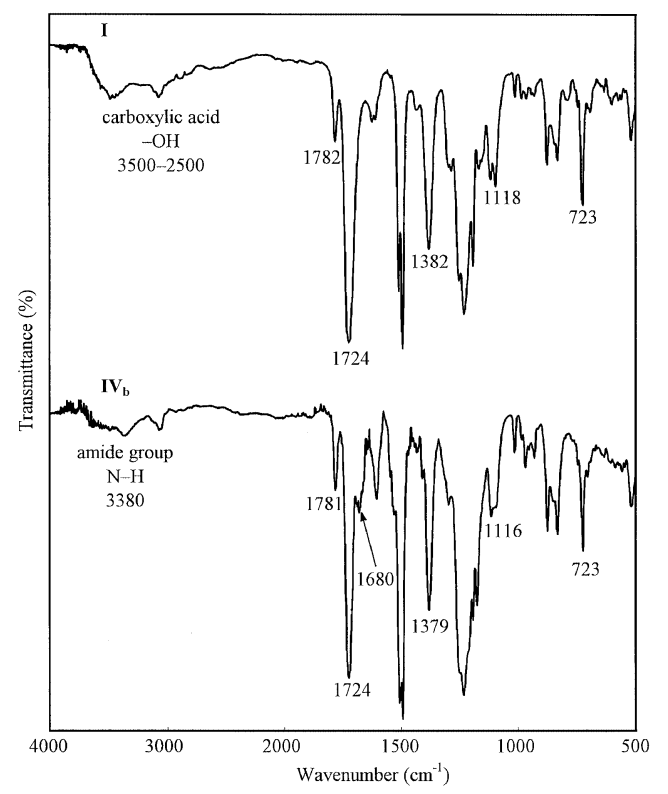

Figure 1. FT-IR spectra of tetraimide-diacid I and poly(amideimide-imide) $\mathbf{I} \mathbf{V}_{\mathrm{b}}$.

est free energy was prepared. From the molar ratio of monomers, $\mathbf{I}^{\prime}$ is a more stable structure among intermediates. Therefore, a higher purity of TIDA I was obtained after the cyclodehydration of $\mathbf{I}^{\prime}$. The FT-IR characteristic absorptions of TIDA I are shown in Figure 1. As TIDA I was prepared, the characteristic absorption bands of the imide ring were observed at 1782, 1724, 1382,1118 , and $723 \mathrm{~cm}^{-1}$, and those of the acid group of TIDA I appeared at $2500-3500 \mathrm{~cm}^{-1}$. The structures of TIDA I were also confirmed by ${ }^{1} \mathrm{H}$ and ${ }^{13} \mathrm{C}$ NMR spectroscopy.

In the ${ }^{1} \mathrm{H}$ NMR spectrum (Figure 2) of $\mathbf{I}$, the protons of TMA and 6FDA moieties resonated at 8.42, $8.41\left(\mathrm{H}_{\mathrm{b}}\right), 8.31\left(\mathrm{H}_{\mathrm{a}}\right), 8.08,8.07\left(\mathrm{H}_{\mathrm{c}}\right) \mathrm{ppm}$ and 8.19, $8.17\left(\mathrm{H}_{\mathrm{i}}\right), 7.98,7.96\left(\mathrm{H}_{\mathrm{h}}\right), 7.76\left(\mathrm{H}_{\mathrm{g}}\right) \mathrm{ppm}$, respectively. Different linkages caused the $\mathrm{H}_{\mathrm{d}, \mathrm{e}, \mathrm{f}}$ and $\mathrm{H}_{\mathrm{d}^{\prime}, \mathrm{e}^{\prime}, \mathrm{f}^{\prime}}$ of $\mathbf{I}$ to shift at different positions, and their signals appeared at higher filed than the rest protons in that it was less affected by other groups. The relative shifts of monomer I were similar to these of model compound II. The protons in TPEQ segment of two monomers appeared at similar shift range, but their splitting patterns were different. From the integrals of protons, it is testified that the proposed structures of TIDA I had formed with high purity. The ${ }^{13} \mathrm{C}$ NMR spectrum of I shows 33 signals (Figure 3), including 5 signals of carbonyl, 23 signals of carbon of benzene, and 5 signals of aliphatic carbon. With their different environments, the carbonyls of imide ring $\left(\mathrm{C}^{2,2^{\prime}, 2^{\prime \prime}, 2^{\prime \prime \prime}}\right)$ displayed four different signals $(168.42,168.40,168.26$, and $168.13 \mathrm{ppm})$. It will give off 24 signals for aromatic carbon of benzene according to the structure of $\mathbf{I}$, but only 23 signals for carbon of benzene were found in the spectrum due to

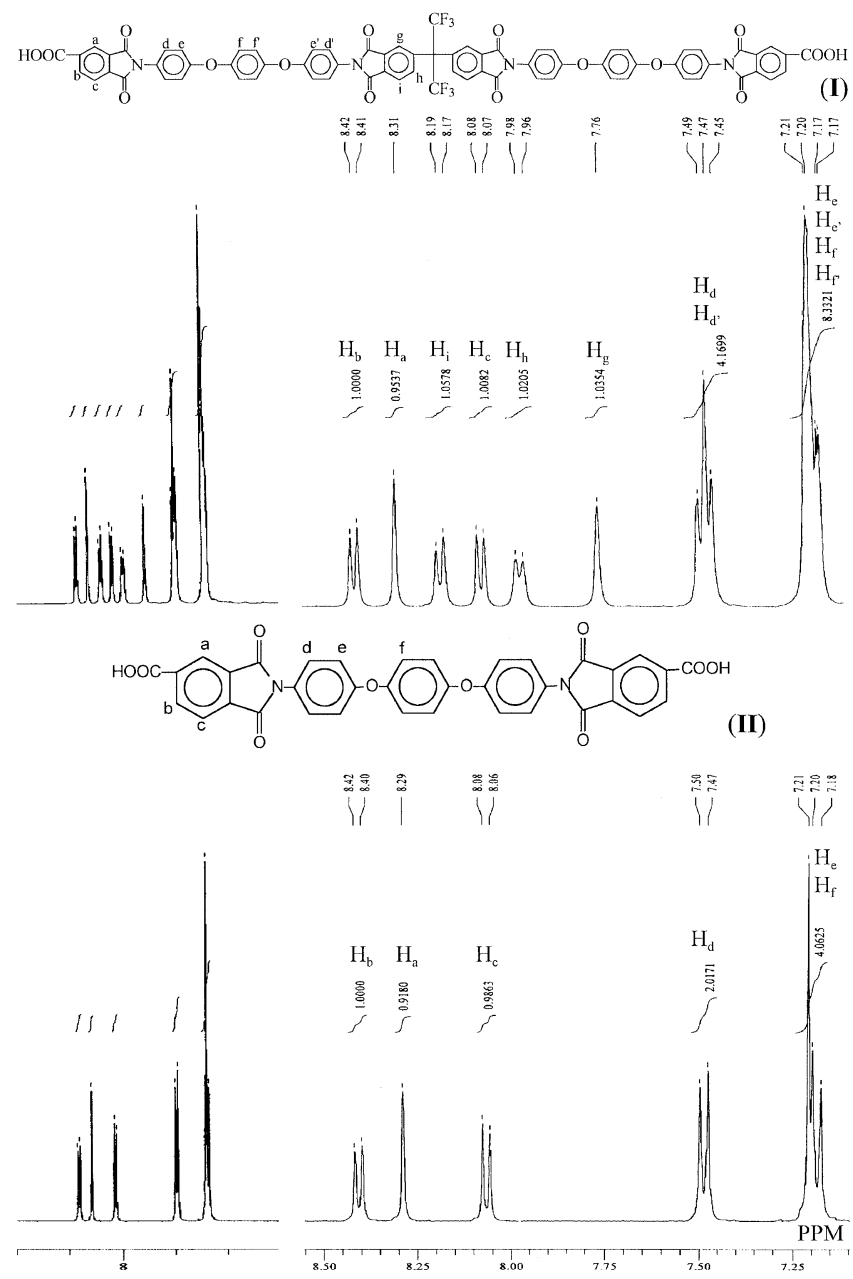

Figure 2. ${ }^{1} \mathrm{H}$ NMR spectra of diacids I and II in DMSO- $d_{6}$.

the overlap shifts of $\mathrm{C}^{14}$ and $\mathrm{C}^{14^{\prime}}$. The chemical shifts of $\mathrm{C}^{9-14}$ were slightly different with those of $\mathrm{C}^{9^{\prime}-14^{\prime}}$ because of different linkages. The splitting of the ${ }^{13} \mathrm{C}$ signals caused by couplings between carbon and fluorine also could be observed in this spectrum. The magnitudes of the one-bond and two-bond carbon-fluorine couplings ${ }^{1} J_{\mathrm{CF}}$ and ${ }^{2} J_{\mathrm{CF}}$ were $290 \mathrm{~Hz}$ and $25 \mathrm{~Hz}$, respectively. Compared with those of the model compound II, the relative shift positions of $\mathrm{C}^{1-14}$ in I were very similar to those in II. Therefore, TIDA I was confirmed in agreement with predictive structure.

\section{Polymer Synthesis}

A series of PAIIs $\mathbf{I V}$ a-m was synthesized from $\mathbf{I}$ and various diamines by means of direct polycondensation with TPP/Py as the condensing agent in NMP in the presence of $\mathrm{CaCl}_{2}$ (Scheme 2). Polymerization can also proceed directly using the resultant solution of diacid synthesis. The synthesis conditions and results of the preparation of PAIIs are summarized in Table I. All the reactions went on smoothly in homogeneous solutions under conditions listed in Table I. The solubility of the polymer and the state of stirring affected the in- 


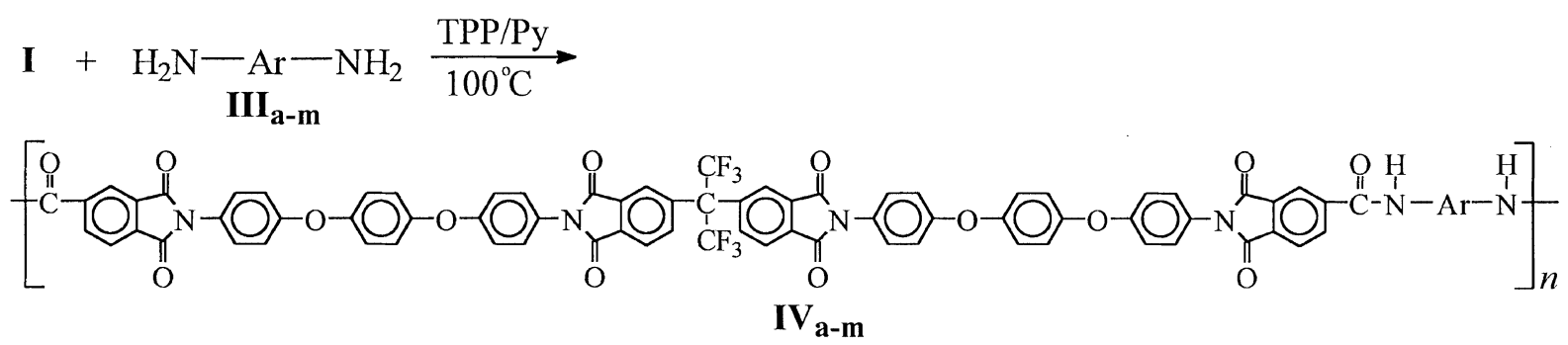

Ar: (a)<smiles>Cc1ccc(I)cc1</smiles>

(b)

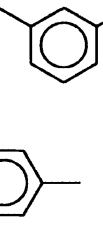

(f)<smiles>Cc1ccc(Sc2ccc(C)cc2)cc1</smiles>

(c)<smiles>Cc1ccc(C)c(C)c1</smiles>

(d)<smiles>Cc1ccc(Oc2ccc(C)cc2)cc1</smiles>

(e)<smiles>Cc1ccc(Cc2ccc(C)cc2)cc1</smiles>

(g)

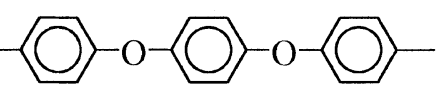

(h)

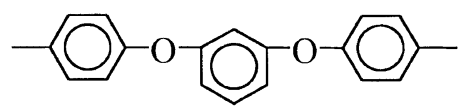

(i)<smiles>Cc1ccc(Oc2ccccc2Oc2ccc(C)cc2)cc1</smiles>

(j)<smiles>Cc1ccc(Oc2ccc(C(C)(C)c3ccc(Oc4ccc(C)cc4)cc3)cc2)cc1</smiles>

(k)<smiles>Cc1ccc(Oc2ccc(C(C)(C)C(F)(F)F)cc2)cc1</smiles>

(1)

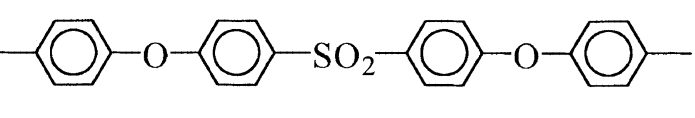

(m)

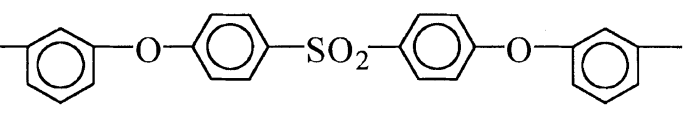

Scheme 2. Synthesis of poly(amide-imide-imide)s.

herent viscosity of the resulting PAIIs significantly. In all cases, higher molecular weights of these polymers could be obtained by using a higher initial reactant concentration and adding a proper amount of supplemental NMP into the viscous reaction medium before the formation of swollen gel. Besides, an advantage of PAII synthesis from large molecular weight $\mathbf{I}$ is that a large product can be obtained by using a small amount of TPP. In other words, when the same amount of TPP is used, the same mole of a polymer in this study and in other reports is formed, but the weight of the polymer in this study is larger. Therefore, new-type PAIIs could significantly reduce the synthetic cost and were thus helpful in industrializing direct polycondensation.

The inherent viscosities of the IV series polymers were $1.0-1.3 \mathrm{dL} \mathrm{g}^{-1}$. All of the PAIIs could be solution cast into transparent and tough films, indicating a high molecular weight. The composition and structures of these PAIIs were characterized by their IR spectra and elemental analyses. A typical IR spectrum is shown in Figure 1. The FT-IR spectrum of polymer $\mathbf{I V}_{\mathrm{b}}$ exhibited characteristic absorption bands for the imide ring at 1781, 1724 (asymmetrical and symmetri- cal $\mathrm{C}=\mathrm{O}$ stretching vibration), $1379(\mathrm{C}-\mathrm{N}$ stretching vibration), 1116, and $723 \mathrm{~cm}^{-1}$ (imide ring deformation). The absorptions of amide groups appeared at $3380(\mathrm{~N}-$ $\mathrm{H}$ stretch) and $1680 \mathrm{~cm}^{-1}(\mathrm{C}=\mathrm{O}$ stretch $)$. The results of the elemental analysis of all the PAIIs are listed in Table I. In all cases, however, the carbon values were found to be lower than the calculated ones for the proposed structures. This is possibly caused by the hygroscopic nature of the amide groups of these polymers. The uptakes of water were in the range of $1.23-2.35 \%$, which could be calculated from the weight change of the vacuum-dried polymer samples after they were exposed in the air at room temperature for $1 \mathrm{~h}$. When the found values were corrected by eliminating the amount of absorbed water, the correction values were in good agreement with the calculated ones.

\section{Properties of Polymer}

The qualitative solubility of PAIIs in various solvents is listed in Table II. Concentration for the solubility tests is $0.05 \mathrm{~g} \mathrm{~mL}^{-1}$. Compared with the IV series and traditional TMA/TPEQ series PAIs $\mathbf{V}$, the IV series polymers clearly exhibited a better solubility. In 
Table I. Synthesis elemental analysis of poly(amide-imide-imide) $\mathrm{s}^{\mathrm{a}}$

\begin{tabular}{|c|c|c|c|c|c|c|c|c|c|}
\hline \multirow{3}{*}{ Polymer } & \multicolumn{2}{|r|}{ Solvent used } & \multirow{3}{*}{$\frac{\eta_{\text {inh }}{ }^{b}}{d L g^{-1}}$} & \multirow{3}{*}{$\frac{\text { Formula }}{M_{\mathrm{w}}}$} & & \multirow{2}{*}{\multicolumn{3}{|c|}{ Elemental analysis $/ \%$}} & \multirow{3}{*}{$\begin{array}{l}\text { Moisture } \\
\frac{\text { uptake }^{\mathrm{d}}}{\%}\end{array}$} \\
\hline & \multirow{2}{*}{$\frac{\mathrm{NMP}}{\mathrm{mL}}$} & \multirow{2}{*}{$\frac{\text { Supplemental NMP }}{\mathrm{mL}}$} & & & & & & & \\
\hline & & & & & & $\mathrm{C}$ & $\mathrm{H}$ & $\mathrm{N}$ & \\
\hline $\mathbf{I} \mathbf{V}_{\mathrm{a}}$ & 5.8 & 3 & $1.0^{\mathrm{e}}$ & $\left(\mathrm{C}_{79} \mathrm{H}_{42} \mathrm{~N}_{6} \mathrm{O}_{14} \mathrm{~F}_{6}\right)_{n}$ & Calcd & 67.14 & 3.00 & 5.95 & \\
\hline & & & & $(1413.22)_{n}$ & Found & 66.08 & 3.12 & 5.78 & 1.58 \\
\hline & & & & & Corrected & 67.12 & 3.07 & 5.87 & \\
\hline $\mathbf{I} \mathbf{V}_{\mathrm{b}}$ & 6.3 & 2 & 1.0 & $\left(\mathrm{C}_{79} \mathrm{H}_{42} \mathrm{~N}_{6} \mathrm{O}_{14} \mathrm{~F}_{6}\right)_{n}$ & Calcd & 67.14 & 3.00 & 5.95 & \\
\hline & & & & $(1413.22)_{n}$ & Found & 65.92 & 3.14 & 5.80 & 1.82 \\
\hline & & & & & Corrected & 67.12 & 3.08 & 5.91 & \\
\hline $\mathbf{I} \mathbf{V}_{\mathrm{c}}$ & 5.8 & 3 & 1.0 & $\left(\mathrm{C}_{80} \mathrm{H}_{44} \mathrm{~N}_{6} \mathrm{O}_{14} \mathrm{~F}_{6}\right)_{n}$ & Calcd & 67.32 & 3.11 & 5.89 & \\
\hline & & & & $(1427.25)_{n}$ & Found & 65.74 & 3.22 & 5.73 & 2.35 \\
\hline & & & & & Corrected & 67.28 & 3.14 & 5.86 & \\
\hline $\mathbf{I} \mathbf{V}_{\mathrm{d}}$ & 7.3 & 2 & 1.3 & $\left(\mathrm{C}_{85} \mathrm{H}_{46} \mathrm{~N}_{6} \mathrm{O}_{15} \mathrm{~F}_{6}\right)_{n}$ & Calcd & 67.82 & 3.08 & 5.58 & \\
\hline & & & & $(1505.32)_{n}$ & Found & 66.63 & 3.17 & 5.38 & 1.75 \\
\hline & & & & & Corrected & 67.80 & 3.11 & 5.47 & \\
\hline $\mathbf{I} \mathbf{V}_{\mathrm{e}}$ & 8.0 & 8 & 1.0 & $\left(\mathrm{C}_{86} \mathrm{H}_{48} \mathrm{~N}_{6} \mathrm{O}_{14} \mathrm{~F}_{6}\right)_{n}$ & Calcd & 68.71 & 3.22 & 5.59 & \\
\hline & & & & $(1503.35)_{n}$ & Found & 67.12 & 3.34 & 5.46 & 2.31 \\
\hline & & & & & Corrected & 68.67 & 3.26 & 5.59 & \\
\hline $\mathbf{I} \mathbf{V}_{\mathrm{f}}$ & 7.2 & 2 & 1.3 & $\left(\mathrm{C}_{85} \mathrm{H}_{46} \mathrm{~N}_{6} \mathrm{O}_{14} \mathrm{~F}_{6} \mathrm{~S}\right)_{n}$ & Calcd & 67.11 & 3.05 & 5.52 & \\
\hline & & & & $(1521.38)_{n}$ & Found & 65.96 & 3.13 & 5.39 & 1.71 \\
\hline & & & & & Corrected & 67.09 & 3.08 & 5.48 & \\
\hline $\mathbf{I} \mathbf{V}_{\mathrm{g}}$ & 6.5 & 6 & $1.0^{\mathrm{e}}$ & $\left(\mathrm{C}_{91} \mathrm{H}_{50} \mathrm{~N}_{6} \mathrm{O}_{16} \mathrm{~F}_{6}\right)_{n}$ & Calcd & 68.42 & 3.15 & 5.26 & \\
\hline & & & & $(1597.42)_{n}$ & Found & 67.50 & 3.28 & 5.09 & 1.34 \\
\hline & & & & & Corrected & 68.40 & 3.23 & 5.16 & \\
\hline $\mathbf{I} \mathbf{V}_{\mathrm{h}}$ & 7.6 & 5 & 1.2 & $\left(\mathrm{C}_{91} \mathrm{H}_{50} \mathrm{~N}_{6} \mathrm{O}_{16} \mathrm{~F}_{6}\right)_{n}$ & Calcd & 68.42 & 3.15 & 5.26 & \\
\hline & & & & $(1597.42)_{n}$ & Found & 67.38 & 3.22 & 5.10 & 1.52 \\
\hline & & & & & Corrected & 68.40 & 3.17 & 5.18 & \\
\hline $\mathbf{I} \mathbf{V}_{\mathrm{i}}$ & 6.3 & 4 & 1.1 & $\left(\mathrm{C}_{91} \mathrm{H}_{50} \mathrm{~N}_{6} \mathrm{O}_{16} \mathrm{~F}_{6}\right)_{n}$ & Calcd & 68.42 & 3.15 & 5.26 & \\
\hline & & & & $(1597.42)_{n}$ & Found & 67.20 & 3.23 & 5.18 & 1.78 \\
\hline & & & & & Corrected & 68.39 & 3.17 & 5.27 & \\
\hline $\mathbf{I} \mathbf{V}_{\mathrm{j}}$ & 7.6 & 6 & 1.3 & $\left(\mathrm{C}_{100} \mathrm{H}_{60} \mathrm{~N}_{6} \mathrm{O}_{16} \mathrm{~F}_{6}\right)_{n}$ & Calcd & 70.01 & 3.53 & 4.90 & \\
\hline & & & & $(1715.60)_{n}$ & Found & 68.84 & 3.63 & 4.80 & 1.67 \\
\hline & & & & & Corrected & 69.99 & 3.57 & 4.88 & \\
\hline $\mathbf{I} \mathbf{V}_{\mathrm{k}}$ & 7.1 & 5 & 1.2 & $\left(\mathrm{C}_{100} \mathrm{H}_{54} \mathrm{~N}_{6} \mathrm{O}_{16} \mathrm{~F}_{12}\right)_{n}$ & Calcd & 65.87 & 2.98 & 4.61 & \\
\hline & & & & $(1823.54)_{n}$ & Found & 65.06 & 3.10 & 4.48 & 1.23 \\
\hline & & & & & Corrected & 65.86 & 3.06 & 4.54 & \\
\hline $\mathbf{I} \mathbf{V}_{1}$ & 6.5 & 7 & 1.1 & $\left(\mathrm{C}_{97} \mathrm{H}_{54} \mathrm{~N}_{6} \mathrm{O}_{18} \mathrm{~F}_{6} \mathrm{~S}\right)_{n}$ & Calcd & 67.05 & 3.13 & 4.84 & \\
\hline & & & & $(1737.58)_{n}$ & Found & 65.64 & 3.26 & 4.69 & 2.10 \\
\hline & & & & & Corrected & 67.02 & 3.19 & 4.79 & \\
\hline $\mathbf{I} \mathbf{V}_{\mathrm{m}}$ & 7.3 & 2 & 1.2 & $\left(\mathrm{C}_{97} \mathrm{H}_{54} \mathrm{~N}_{6} \mathrm{O}_{18} \mathrm{~F}_{6} \mathrm{~S}\right)_{n}$ & Calcd & 67.05 & 3.13 & 4.84 & \\
\hline & & & & $(1737.58)_{n}$ & Found & 65.81 & 3.19 & 4.66 & 1.85 \\
\hline & & & & & Corrected & 67.03 & 3.13 & 4.75 & \\
\hline
\end{tabular}

${ }^{\text {a}}$ Polymerization was carried out with $1 \mathrm{mmol}$ of each monomer in NMP, $1.5-1.9 \mathrm{~mL}$ of pyridine. $0.2-0.4 \mathrm{~g}$ of CaCl 2 and $0.6 \mathrm{~mL}$ of triphenyl phosphite at $100^{\circ} \mathrm{C}$ for $3 \mathrm{~h}$. ${ }^{b}$ Measured at a polymer concentration of $0.5 \mathrm{~g} \mathrm{dL}^{-1}$ in DMAc at $30^{\circ} \mathrm{C}$. ${ }^{\circ}$ For $\mathrm{C}$ and N: Corrected value $=$ found value $\times(100 \%+$ moisture uptake $\%)$. For $\mathrm{H}$ : Corrected value $=$ found value $\times(100 \%-$ moisture uptake $\%) .{ }^{\mathrm{d}}$ Moisture uptake $(\%)=\left(W-W_{0}\right) / W_{0} \times 100 \% ; W=$ weight of polymer sample after standing at room temperature, and $W_{0}=$ weight of polymer sample after dried in vacuum at $100^{\circ} \mathrm{C}$ for $10 \mathrm{~h}$. ${ }^{e}$ Measured at a polymer concentration of $0.5 \mathrm{~g} \mathrm{dL}^{-1}$ in $\mathrm{NMP}+5 \% \mathrm{LiCl}$ at $30^{\circ} \mathrm{C}$.

series $\mathbf{V}$, only $\mathbf{V}_{\mathrm{d} \text {,h }}$ were partially soluble in NMP. On the contrary, the solubility of most PAIIs IV was significantly improved, and $\mathbf{I V}_{\mathrm{d}, \mathrm{f}, \mathrm{g}, \mathrm{h}}$ were soluble in the tested solvents. $\mathbf{I V}_{\mathrm{a}}$ including rigid $p$-phenylene in diamine showed a limited solubility but was still soluble in NMP. The good solubility of these polymers IV might be due to the presence of the flexible ether and bulky hexafluoropropane groups in TIDA I, which dis- turbed the co-planarity of aromatic units to reduce the packing efficiency and the crystallinity.

All the polymers could afford good-quality, creasable films by casting from DMAc or NMP solution. The tensile properties are summarized in Table III. All of the films necked under tension, indicating a ductile nature. These films had strengths at yield of 84-109 MPa, strengths at break of 80-101 MPa, elongations at break 


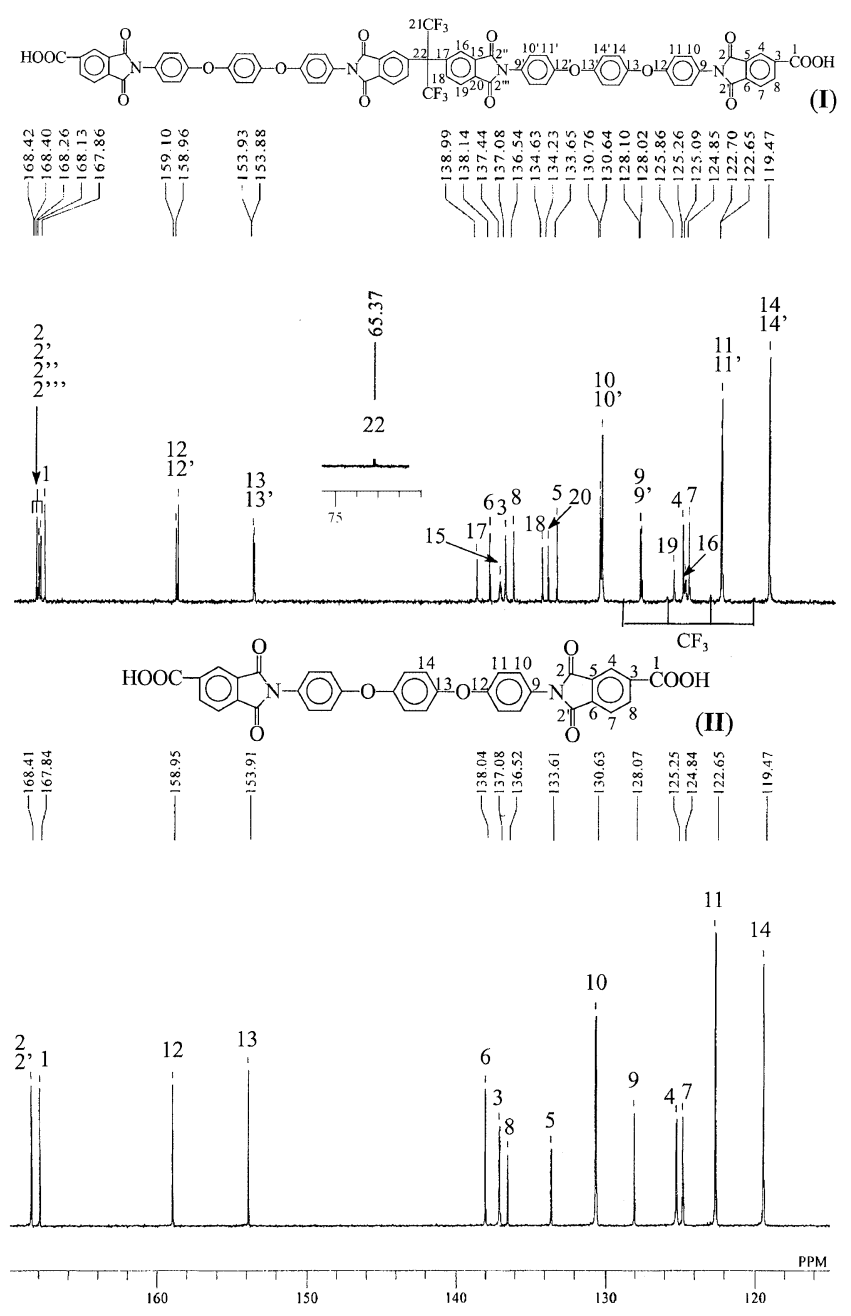

Figure 3. ${ }^{13} \mathrm{C}$ NMR spectra of diacids I and II in DMSO- $d_{6}$.

of $10-17 \%$, and initial moduli of $2.0-2.4 \mathrm{GPa}$. On comparing tensile properties of polymers IV with their analogous PAI $\mathbf{V}$, series IV polymers exhibited higher strengths at break as a result of a higher proportion of the imide group in the main chain. Most of the polymers $\mathbf{V}$ couldn't be cast into films or formed brittle films, but all the PAIIs IV showed a good film-forming ability. Therefore, the tensile properties of PAIs $\mathbf{V}$ could be modified as well as PAIIs IV by copolymerization.

The thermal properties of all the PAIIs were evaluated by TGA and DSC. The results of all polymers are summarized in Table IV. DSC measurements were conducted at a heating rate of $15^{\circ} \mathrm{C} \mathrm{min}{ }^{-1}$ in nitrogen. Quenching from the elevated temperature (approximately $400^{\circ} \mathrm{C}$ ) to room temperature in air gave predominantly amorphous samples so that the glass transition temperatures $\left(T_{\mathrm{g}}\right)$ of PAIIs could be easily measured in the second heating traces of DSC. The $T_{\mathrm{g}}$ values of these PAIIs were in the range $260-289^{\circ} \mathrm{C}$, depending on the structure of the diamine component and following with the increasing stiffness of the polymer backbones. For isomers, $\mathbf{I V}_{\mathrm{a}, \mathrm{g}, 1}$, whose diamine struc-
Table II. Solubility of poly(amide-imide-imide) $\mathrm{s}^{\mathrm{a}}$

\begin{tabular}{lcccccc}
\hline \multirow{2}{*}{ Polymer } & \multicolumn{7}{c}{ Solvent $^{\mathrm{b}}$} \\
\cline { 2 - 7 } & NMP & DMAc & DMF & DMSO & $m$-Cresol & Py \\
\hline $\mathbf{I V}_{\mathrm{a}}$ & + & - & - & - & - & - \\
$\mathbf{I V}_{\mathrm{b}}$ & + & + & + & + & + & + \\
$\mathbf{I V}_{\mathrm{c}}$ & + & + & + & + & + & + \\
$\mathbf{I V}_{\mathrm{d}}$ & + & + & + & + & \pm & $\mathrm{S}$ \\
$\mathbf{I V}_{\mathrm{e}}$ & + & + & + & + & + & \pm \\
$\mathbf{I V}_{\mathrm{f}}$ & + & + & + & + & + & + \\
$\mathbf{I V}_{\mathrm{g}}$ & + & + & + & + & + & + \\
$\mathbf{I V}_{\mathrm{h}}$ & + & + & + & + & + & + \\
$\mathbf{I V}_{\mathrm{i}}$ & + & + & + & + & + & + \\
$\mathbf{I V}_{\mathrm{j}}$ & + & + & + & + & + & + \\
$\mathbf{I V}_{\mathrm{k}}$ & + & + & + & + & + & + \\
$\mathbf{I V}_{\mathrm{l}}$ & + & + & + & + & + & + \\
$\mathbf{I V}_{\mathrm{m}}$ & + & + & + & + & + & + \\
& & & & & & \\
$\mathbf{V}_{\mathrm{d}}$ & \pm & - & - & - & - & - \\
$\mathbf{V}_{\mathrm{f}}$ & - & - & - & - & - & - \\
$\mathbf{V}_{\mathrm{g}}$ & - & - & - & - & - & - \\
$\mathbf{V}_{\mathrm{h}}$ & \pm & - & - & - & - & - \\
\hline
\end{tabular}

${ }^{\text {a }}$ Solubility: measured at a polymer concentration of $0.05 \mathrm{~g}$ $\mathrm{mL}^{-1} . \quad+$, soluble at room temperature; \pm , partially sol-

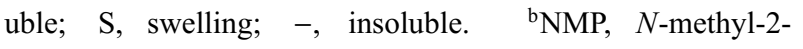
pyrrolidone; DMAc, $N, N$-dimethylacetamide; DMF, $N, N$ dimethylformamide; DMSO, dimethyl sulfoxide; Py, pyridine.

Table III. Tensile properties of poly(amide-imide-imide)

\begin{tabular}{|c|c|c|c|c|}
\hline \multicolumn{5}{|c|}{ films $\mathrm{s}^{\mathrm{a}}$} \\
\hline Polymer & $\begin{array}{l}\text { Strength } \\
\text { at yield } \\
\mathrm{MPa}\end{array}$ & $\begin{array}{l}\text { Strength } \\
\frac{\text { at break }}{\mathrm{MPa}}\end{array}$ & $\begin{array}{c}\text { Elongation } \\
\text { to break } \\
\%\end{array}$ & $\begin{array}{c}\begin{array}{c}\text { Initial } \\
\text { modulus }\end{array} \\
\frac{\mathrm{GPa}}{}\end{array}$ \\
\hline $\mathbf{I V}_{\mathrm{a}}{ }^{\mathrm{b}}$ & 97 & 90 & 11 & 2.1 \\
\hline $\mathbf{I V} \mathbf{b}_{\mathrm{b}}$ & 98 & 93 & 14 & 2.3 \\
\hline $\mathbf{I} \mathbf{V}_{\mathrm{c}}$ & 109 & 101 & 17 & 2.4 \\
\hline $\mathbf{I} \mathbf{V}_{\mathrm{d}}$ & 94 & 90 & 14 & 2.2 \\
\hline $\mathbf{I V}$ e & 86 & 83 & 10 & 2.2 \\
\hline $\mathbf{I} \mathbf{V}_{\mathrm{f}}$ & 87 & 85 & 12 & 2.0 \\
\hline $\mathbf{I V} \mathbf{V}_{\mathrm{g}}$ & 103 & 99 & 13 & 2.2 \\
\hline $\mathbf{I} \mathbf{V}_{\mathrm{h}}$ & 97 & 90 & 12 & 2.0 \\
\hline $\mathbf{I} \mathbf{V}_{\mathrm{i}}$ & 95 & 81 & 10 & 2.0 \\
\hline $\mathbf{I} \mathbf{V}_{\mathrm{j}}$ & 84 & 80 & 12 & 2.1 \\
\hline $\mathbf{I} \mathbf{V}_{\mathrm{k}}$ & 90 & 83 & 13 & 2.1 \\
\hline $\mathbf{I} \mathbf{V}_{1}$ & 99 & 95 & 17 & 2.3 \\
\hline $\mathbf{I} \mathbf{V}_{\mathrm{m}}$ & 97 & 93 & 15 & 2.1 \\
\hline $\mathbf{V}_{\mathrm{b}}$ & 86 & 83 & 24 & 2.1 \\
\hline $\mathbf{V}_{\mathrm{c}}$ & 89 & 83 & 45 & 2.3 \\
\hline $\mathbf{V}_{\mathrm{k}}$ & - & 62 & 9 & 1.5 \\
\hline $\mathbf{V}_{1}$ & - & 54 & 4 & 1.9 \\
\hline
\end{tabular}

${ }^{\mathrm{a}}$ Films were cast from polymer solutions of DMAc. ${ }^{\mathrm{b}}$ Film was cast from polymer solution of NMP $+0.5 \% \mathrm{LiCl}$.

tures were all para-oriented, showed higher $T_{\mathrm{g}}$ values than did $\mathbf{I} \mathbf{V}_{\mathrm{b}, \mathrm{h}, \mathrm{m}}$, derived from meta-oriented diamines. $\mathbf{I} \mathbf{V}_{\mathrm{j}}$ had structures analogous to $\mathbf{I} \mathbf{V}_{\mathrm{k}}$, but substituent magnitude of $-\mathrm{CF}_{3}$ was much larger than $-\mathrm{CH}_{3}$, leading to higher $T_{\mathrm{g}}$ value. When comparing PAIIs IV with 
Table IV. Thermal data of poly(amide-imide-imide)s

\begin{tabular}{|c|c|c|c|c|}
\hline \multirow{3}{*}{ Polymer } & \multirow{3}{*}{$\frac{\mathrm{DSC}}{T_{\mathrm{g}}{ }^{\mathrm{a}} /{ }^{\circ} \mathrm{C}}$} & \multicolumn{3}{|c|}{ TGA } \\
\hline & & \multicolumn{2}{|c|}{ Decomposition temperature ${ }^{\mathrm{b}} /{ }^{\circ} \mathrm{C}$} & \multirow{2}{*}{$\begin{array}{c}\mathrm{wt} \% \text { Residual at } \\
800^{\circ} \mathrm{C} \text { in } \mathrm{N}_{2}\end{array}$} \\
\hline & & In air & In nitrogen & \\
\hline $\mathbf{I} \mathbf{V}_{\mathrm{a}}$ & 289 & 528 & 527 & 50 \\
\hline $\mathbf{I} \mathbf{V}_{\mathrm{b}}$ & 281 & 533 & 538 & 56 \\
\hline $\mathbf{I} \mathbf{V}_{\mathrm{c}}$ & 280 & 537 & 549 & 53 \\
\hline $\mathbf{I} \mathbf{V}_{\mathrm{d}}$ & 274 & 532 & 545 & 51 \\
\hline $\mathbf{I} \mathbf{V}_{\mathrm{e}}$ & 281 & 535 & 550 & 50 \\
\hline $\mathbf{I V}_{\mathrm{f}}$ & 280 & 537 & 554 & 50 \\
\hline $\mathbf{I} \mathbf{V}_{\mathrm{g}}$ & 268 & 536 & 546 & 56 \\
\hline $\mathbf{I} \mathbf{V}_{\mathrm{h}}$ & 260 & 543 & 550 & 57 \\
\hline $\mathbf{I} \mathbf{V}_{\mathrm{i}}$ & 266 & 545 & 555 & 59 \\
\hline $\mathbf{I} \mathbf{V}_{\mathrm{j}}$ & 261 & 520 & 539 & 52 \\
\hline $\mathbf{I} \mathbf{V}_{\mathrm{k}}$ & 266 & 526 & 545 & 55 \\
\hline $\mathbf{I} \mathbf{V}_{1}$ & 277 & 530 & 544 & 54 \\
\hline $\mathbf{I} \mathbf{V}_{\mathrm{m}}$ & 260 & 531 & 546 & 55 \\
\hline $\mathbf{V}_{\mathrm{c}}$ & 292 & 515 & 526 & 58 \\
\hline $\mathbf{V}_{\mathrm{e}}$ & $-^{\mathrm{c}}$ & 501 & 529 & 48 \\
\hline $\mathbf{V}_{\mathrm{f}}$ & - & 507 & 541 & 48 \\
\hline $\mathbf{V}_{1}$ & 269 & 525 & 521 & 49 \\
\hline
\end{tabular}

PAIs IV, the IV series displayed lower $T_{\mathrm{g}}$ values than the corresponding $\mathbf{V}$. This was attributed to the flexible ether and hindered hexafluoroisopropylidene linkages of TIDA I, which disturbed the co-planarity of aromatic units to reduce the packing efficiency.

The thermal stability of the PAIIs was examined by TGA measurements. The temperatures at $10 \%$ weight loss $\left(T_{10}\right)$ and their char yields at $800^{\circ} \mathrm{C}$ in nitrogen atmosphere were determined from the original thermograms. The $T_{10}$ values of polymers IV were in the range of $527-555^{\circ} \mathrm{C}$ in nitrogen and $520-545^{\circ} \mathrm{C}$ in air, respectively. The fluorine-containing $\mathbf{I} \mathbf{V}_{\mathrm{k}}$ had a slightly better thermal stability than its nonfluoro analogous $\mathbf{I} \mathbf{V}_{\mathbf{j}}$ did because the $\mathrm{C}-\mathrm{F}$ bond of the $\mathrm{CF}_{3}$ group is stronger than that of the $\mathrm{CH}_{3}$ group. When compared with the $\mathbf{V}$ series, series IV had a char yield close to series $\mathbf{V}$ did, but the IV series exhibited higher $T_{10}$ values under nitrogen and air atmospheres as a result of a higher proportion of the thermostable imide group in the main chain. Figure 4 shows typical TGA curves of PAII $\mathbf{I V}_{\mathrm{e}}$ and PAI $\mathbf{V}_{\mathrm{e}}$. The thermogravimetric traces indicated that polymers IVpossessed a high thermal stability with no significant weight loss up to approximately $450^{\circ} \mathrm{C}$ and had a char yield above $50 \%$.

\section{CONCLUSIONS}

Unlike traditional diimide-diamide or imide-amide PAIs, a series of novel PAIIs with alternating four imide

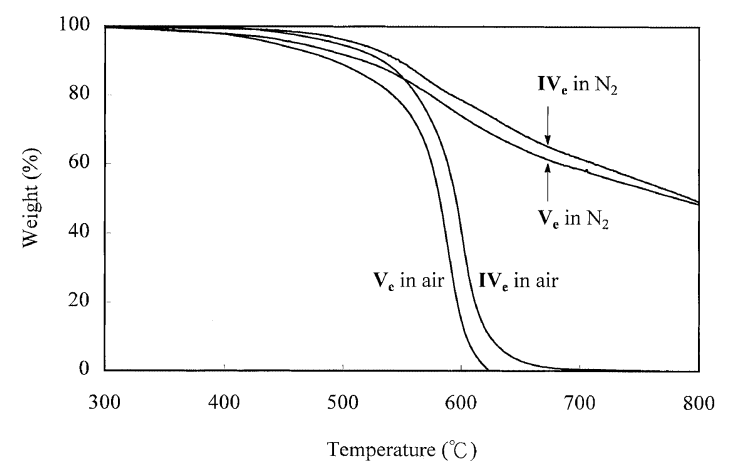

Figure 4. TGA curves of polymers $I V_{e}$ and $\mathbf{V}_{\mathrm{e}}$ at a heating rate of $20^{\circ} \mathrm{C} \mathrm{min}^{-1}$.

and two amide groups was synthesized. The polymers showed excellent solubility in a variety of amide-type solvents and even in less polar solvents. These polymers were characterized by good film-forming ability, a wide temperature range between $T_{\mathrm{g}}$ and decomposition temperature, and excellent thermal stability as well as good tensile properties, demonstrating a good combination of properties and processability. Thus, they were considered as new candidates for processable high-performance polymeric materials.

Acknowledgment. The authors are grateful to the National Science Council of the Republic of China for the support of this work (Grant NSC 90-2216-E-036016). 


\section{REFERENCES}

1. C. Feger, M. M. Khojasteh, and M. S. Htoo, "Advances in Polyimide Science and Technology", Technomic Publishing Co. Inc., Lancaster, 1993.

2. M. J. M. Adadie and B. Sillion, "Polyimides and Other High-Temperature Polymers", Elsevier Science Publishens B. V., Amsterdam, 1991.

3. K. L. Mittal, "Polyimide: Synthesis, Characterization, and Application”, vol. I \& II, Plemnum Publishing Corporation, New York, N.Y., 1984.

4. C. Feger, M. M. Khojasteh, and J. E. McGrath, "Polyimides, Chemistry and Characterization", Elsevier Science Publishers B. V., Amsterdam, 1989.

5. D. Wilson, H. D. Stenzenberger, and P. M. Hergenrother, "Polyimides", Blackie, New York, N.Y., 1990.

6. P. E. Cassidy, "Thermally Stable Polymers", Marcel Dekker, Inc., New York, N.Y., 1980.

7. H. H. Yang, "Aromatic High-Strength Fibers", John Wiley \& Sons, Inc., New York, N.Y., 1986.

8. V. L. Bell, B. L. Stump, and H. Gager, J. Polym. Sci., Polym. Chem. Ed., 14, 2275 (1976).

9. T. Takekoshi, J. G. Wirth, D. R. Heath, J. E. Kochanocoski, J. S. Manello, and M. T. Webber, J. Polym. Sci., Part A: Polym. Chem., 18, 3069 (1980).

10. G. C. Eastmond and J. Paprotny, Macromolecules, 28, 2140 (1995).

11. G. C. Eastmond, J. Paprotny, and R. S. Irwin, Macromolecules, 29, 1382 (1996).

12. C. P. Yang and J. H. Lin, J. Polym. Sci., Part A: Polym. Chem., 31, 2153 (1993).

13. M. Sato and M. Yokoyama, Eur. Polym. J., 15, 733 (1979).

14. Q. Jin, T. Yamashita, and K. Horie, J. Polym. Sci., Part A: Polym. Chem., 32, 503 (1994).
15. C. P. Yang and S. H. Hsiao, Makromol. Chem., 190, 2119 (1989).

16. H. E. Frey, U. S. Patent 3300420 (Jan. 24, 1967).

17. Hitachi Chem. Co. Ltd., Fr. Patent 1473600 (Mar. 17, 1967).

18. J. Sambeth, Fr. Patent 1498015 (Oct. 13, 1967).

19. M. Kakimoto, R. Akiyama, Y. S. Negi, and Y. Imai, J. Polym. Sci., Part A: Polym. Chem., 26, 99 (1988).

20. Y. Imai, N. N. Maldar, and M. Kakimoto, J. Polym. Sci., Part A: Polym. Chem., 23, 2077 (1985).

21. J. F. Dezern, J. Polym. Sci., Part A: Polym. Chem., 26, 2157 (1988).

22. G. M. Bower and L. W. Frost, J. Polym. Sci., Part A-1: Polym. Chem., 3135 (1963).

23. C. P. Yang, S. H. Hsiao, and J. H. Lin, Makromol. Chem., 193, 1299 (1992).

24. S. H. Hsiao and C. P. Yang, Makromol. Chem., 191, 155 (1990).

25. C. P. Yang, J. M. Cheng, and S. H. Hsiao, Makromol. Chem., 193, 445 (1992).

26. C. P. Yang, J. Polym. Sci., Polym. Chem. Ed., 17, 3255 (1979).

27. C. P. Yang, S. H. Hsiao, and J. H. Lin., J. Polym. Sci., Part A: Polym. Chem., 30, 1865 (1992).

28. S. H. Hsiao and C. P. Yang, J. Polym. Sci., Part A: Polym. Chem., 28, 2169 (1990).

29. S. Maiti and A. Ray, J. Appl. Polym. Sci., 28, 225 (1983).

30. S. Maiti and A. Ray, J. Polym. Sci., Part A: Polym. Chem., 21, 999 (1983).

31. S. H. Hsiao and C. P. Yang, J. Polym. Sci., Part A: Polym. Chem., 28, 1149 (1990).

32. C. P. Yang, S. H. Hsiao, and W. L. Chou, J. Polym. Res., 2, 179 (1995).

33. C. P. Yang and J. J. Cherng, J. Polym. Sci., Part A: Polym. Chem., 33, 2209 (1995).

34. C. P. Yang and S. H. Hsiao, J. Appl. Polym. Sci., 30, 2883 (1985). 